\title{
超低高度衛星技術試験機「つばめ」（SLATS）による地球観測
}

\section{Regional Observation by Super Low Altitude Test Satellite "TSUBAME" (SLATS)}

\author{
星野 宏和*・此上一也*・金子豊*・佐々木雅範* \\ Hirokazu HOSHINO, Kazuya KONOUE \\ Yutaka KANEKO and Masanori SASAKI
}

\begin{abstract}
SLATS is the first test satellite of JAXA to demonstrate operations at "super low orbit" below $400 \mathrm{~km}$ altitude, almost never used for long-life remote sensing. Lower altitudes will bring benefits for Earth observation such as higher resolution optical imaging and higher Signal/Noise ratio of Synthetic Aperture Radar. Small and High Resolution Optical Sensor (SHIROP) is a panchromatic camera to achieve under 1 meter resolution from super low altitudes. Pointing accuracy and image quality, which are influenced by atmospheric drag, ion engine and Time Delay Integration (TDI), are going to be evaluated. Techniques acquired by SLATS are planned to be used for future regional observation.
\end{abstract}

Keywords : SLATS, Low Altitude, Small Satellite, SHIROP

\section{1.はじめに}

宇宙航空研究開発機構 (JAXA) は, 平成29年度の打 上げに向けて超低高度衛星技術試験機「つばめ」 SLATS (Super Low Altitude Test Satellite) を開 発している。

高度200-300km 台の超低高度は図 1 に示すように 従来の地球観測衛星の高度よりも大気密度が高く, 大 気抵抗の影響が大きい。また，紫外線により酸素分子 から解離した反応性の高い原子状酸素が主成分とな

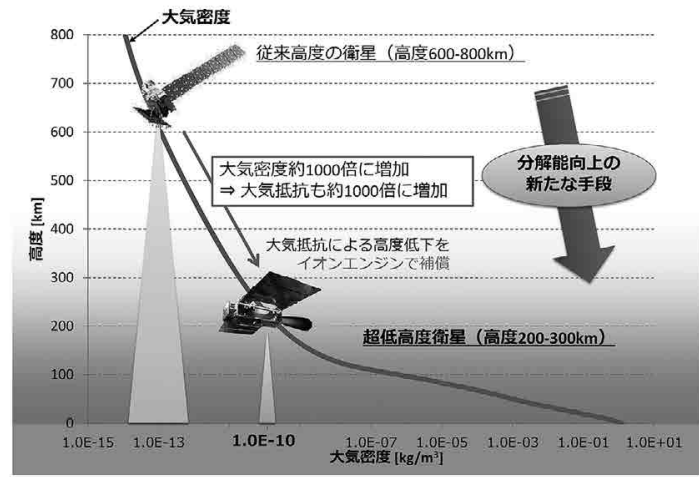

図 1. 大気密度の高度推移と超低高度衛星が航行する高度

*宇宙航空研究開発機構

「写真測量とリモートセンシング」VOL. 56, NO. 5, 2017
り, 衛星の熱制御材を損傷させることが知られている。 超低高度では観測幅が狭くなることから全球観測のリ
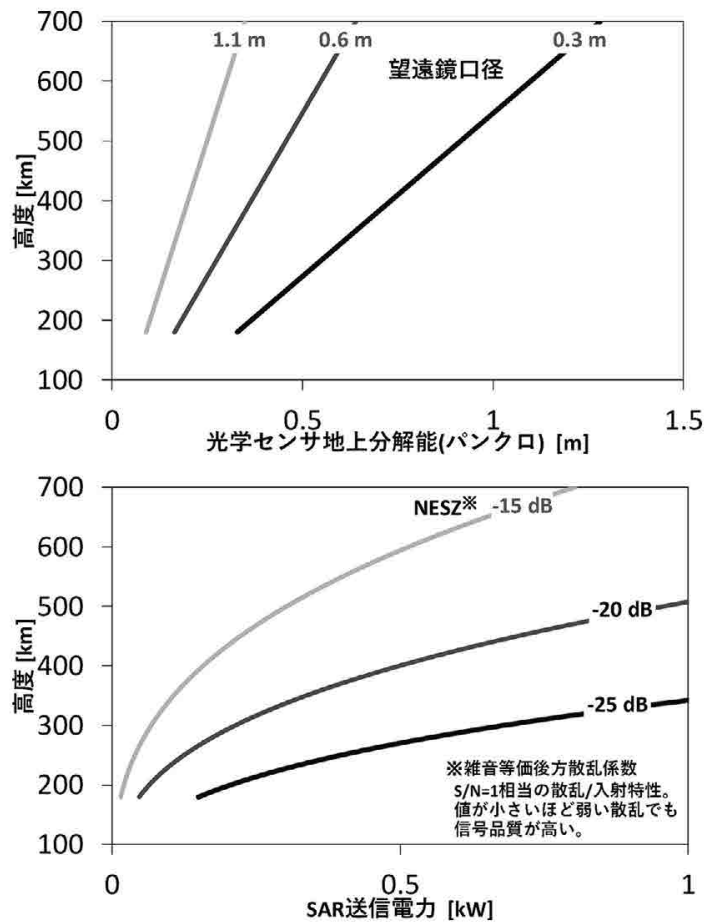

図 2.高度に応じた光学センサ地上分解能およびSAR 送 信電力変化 
モートセンシングにはこれまでほとんど使用されてこ なかったが, 図 2 に示すように光学センサの高分解能 化や，合成開ロレーダSAR（Synthetic Aperture Radar）など電波を用いるレーダの $\mathrm{S} / \mathrm{N}$ 向上・送信電 力低減の利点がある。

\section{2.ミッション概要}

SLATS は「超低高度衛星技術の実証」「大気密度 データの取得」「原子状酸素デー夕の取得」「小型高分 解能光学セン州による高分解能撮像」の 4 つを目的と して，表 1 に示すサクセスクライテリアを設定してい る。

SLATS は H-IIA ロケットから分離後, 図 3 に示す 軌道高度プロファイルで高度を低下し， 1 年近い軌道 遷移を経て，回帰日数 1 日で16周回（軌道周期90分） の高度 $268 \mathrm{~km}$ 以下において，イオンエンジンを稼働し て高度保持を行う。

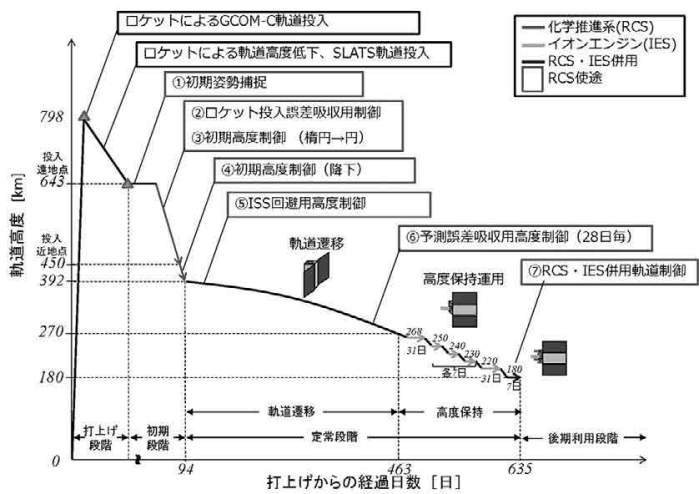

図 3.SLATS 軌道高度プロファイル

\section{3．衛星・センサ概要}

SLATS は大気抵抗の影響を小さくするため，図 4 に示すように断面積が小さい形状である。SLATSの 主要諸元を表 2 に示す。

SLATS の軌道は軌道面の回転が地球の公転の角速

表 1.SLATS サクセスクライテリア

\begin{tabular}{|c|c|c|c|}
\hline \multirow{2}{*}{ 目的 } & \multicolumn{3}{|l|}{ 達成目標 } \\
\hline & ミニマムサクセス*2 & フルサクセス*1 & エクストラサクセス*2 \\
\hline $\begin{array}{l}\text { 超低高度衛星 } \\
\text { 技術の実証 }\end{array}$ & $\begin{array}{l}\text { 超低高度軌道への投入が成功する } \\
\text { こと } \\
\text { 【判断時期：高度 } 268 \mathrm{~km} \text { 到達時点】 }\end{array}$ & $\begin{array}{l}\text { (1)高度*3220km(ノミナル)において, } 27 \text { 日間 } \\
\text { 以上, 自律的に高度保持を実施し, 高度保 } \\
\text { 持精度 } \pm 1 \mathrm{~km}(1 \sigma) \text { を満足すること } \\
\text { (2)異なる高度から光学センサにより撮影でき } \\
\text { ること }\end{array}$ & $\begin{array}{l}\text { 緊急高度上昇運用の有用性を示せる } \\
\text { こと }\end{array}$ \\
\hline $\begin{array}{l}\text { 大気密度デー } \\
\text { 夕の取得*4 }\end{array}$ & $\begin{array}{l}\text { 高度 } 268 \mathrm{~km} \text { より高い高度におい } \\
\text { て,大気密度に関するデー夕を取得 } \\
\text { できること } \\
\text { 【判断時期：高度 } 268 \mathrm{~km} \text { 到達時点】 }\end{array}$ & $\begin{array}{l}\text { 高度 } 268 \mathrm{~km} \text { から } 180 \mathrm{~km} \text { において，90日間の } \\
\text { 大気密度に関するデータを取得できること }\end{array}$ & $\begin{array}{l}\text { (1)高度 } 268 \mathrm{~km} \text { から } 180 \mathrm{~km} \text { において, } \\
90 \text { 日間を超えて大気密度に関す } \\
\text { るデー夕を取得できること } \\
\text { (2)高度 } 180 \mathrm{~km} \text { より低い高度におい } \\
\text { て, 大気密度に関するデー夕を取 } \\
\text { 得できること }\end{array}$ \\
\hline \multirow[t]{2}{*}{$\begin{array}{l}\text { 原子状酸素 } \\
\text { デー夕の取 } \\
\text { 得*4 }\end{array}$} & $\begin{array}{l}\text { 原子状酸素衝突フルエンスセンサ } \\
\text { が正常に動作すること } \\
\text { 【判断時期：打上げ } 3 \text { ヶ月後】 }\end{array}$ & $\begin{array}{l}\text { 高度 } 268 \mathrm{~km} \text { から } 180 \mathrm{~km} \text { において, } 90 \text { 日間の } \\
\text { 原子状酸素衝突フルエンス }\left(\mathrm{F}_{\mathrm{AO}}\right) \text { を計測でき } \\
\text { ること }\end{array}$ & $\begin{array}{l}\text { (1)高度 } 268 \mathrm{~km} \text { から } 180 \mathrm{~km} \text { において, } \\
90 \text { 日間を超えて } \mathrm{F}_{\mathrm{AO}} \text { を計測できる } \\
\text { こと } \\
\text { (2)高度 } 180 \mathrm{~km} \text { より低い高度におい } \\
\quad \text { て, } \mathrm{F}_{\mathrm{AO}} \text { を計測できること }\end{array}$ \\
\hline & $\begin{array}{l}\text { 材料劣化モニ夕機器の全機能が正 } \\
\text { 常に動作すること } \\
\text { 【判断時期：打上げ } 3 \text { ヶ月後】 }\end{array}$ & $\begin{array}{l}\text { 高度 } 180 \mathrm{~km} \text { 以上において, 材料劣化状況を原 } \\
\text { 子状酸素衝突フルエンスと共に取得できるこ } \\
\text { と }\end{array}$ & $\begin{array}{l}\text { 原子状酸素による材料劣化について } \\
\text { 新たな知見が得られること }\end{array}$ \\
\hline $\begin{array}{l}\text { 小型高分解能 } \\
\text { 光学センサに } \\
\text { よる高分解能 } \\
\text { 撮像 }\end{array}$ & $\begin{array}{l}\text { 小型高分解能光学センサが正常に } \\
\text { 動作し，撮像ができること } \\
\text { 【判断時期：高度 } 268 \mathrm{~km} \text { 到達時点】 }\end{array}$ & $\begin{array}{l}\text { 衛星姿勢と協調制御による画質向上の効果や } \\
\text { 大気抵抗及びイオンエンジン噴射による画質 } \\
\text { への影響が評価できること }\end{array}$ & $\begin{array}{l}\text { 超低高度軌道 (高度 } 268 \mathrm{~km} \text { 以下) に } \\
\text { おいて, 衛星姿勢との協調制御によ } \\
\text { る画質向上の効果や大気抵抗及びイ } \\
\text { オンエンジン噴射による画質への影 } \\
\text { 響を評価できること。 }\end{array}$ \\
\hline
\end{tabular}

* 1：フルサクセスの達成判断時期は全て定常段階終了時とする。

* 2 : ミニマム/エクストラサクセスは，項目ごとに達成判断をする。

* 3 : 高度は「平均軌道長半径一赤道半径」の值とする。

* 4 ：ミッション期間中に取得できるデー夕を用い，環境モデルの評価解析を行う。 


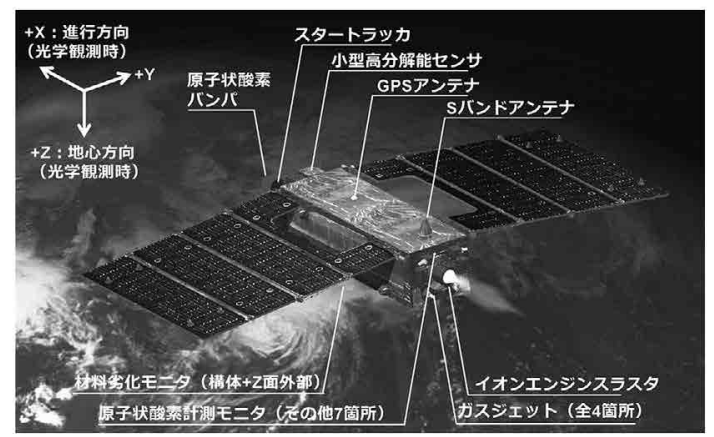

図 4.SLATS 軌道上外観図

表 2. SLATS 主要諸元

\begin{tabular}{|c|c|c|}
\hline \multirow{3}{*}{$\begin{array}{c}\text { 項目 } \\
\text { 軌道高度 } \\
\text { (太陽非同期) }\end{array}$} & \multicolumn{2}{|r|}{ 諸元 } \\
\hline & 軌道投入時 & $643 \times 450 \mathrm{~km}$ (楕円) \\
\hline & 高度保持時 & $268 \sim 180 \mathrm{~km}$ \\
\hline サイズ & \multicolumn{2}{|c|}{$2.5 \mathrm{~m}(\mathrm{X}) \times 5.2 \mathrm{~m}(\mathrm{Y}) \times 0.9 \mathrm{~m} \quad(\mathrm{Z})$} \\
\hline 質量 & \multicolumn{2}{|c|}{$400 \mathrm{~kg}$} \\
\hline 発生電力 & \multicolumn{2}{|c|}{$1,174 \mathrm{~W}$ 以上 } \\
\hline センサ & \multicolumn{2}{|c|}{$\begin{array}{l}\text { 原子状酸素衝突フルエンスモニタ } \\
\text { 材料劣化モニタ } \\
\text { 小型光学センサ } \\
\text { 小型高分解能光学センサ }\end{array}$} \\
\hline 打上げ & \multicolumn{2}{|c|}{ 平成29年度（2017年度） } \\
\hline ミッション期間 & \multicolumn{2}{|c|}{ 打上げ後 2 年 } \\
\hline
\end{tabular}

度よりも速い太陽非同期軌道であり，降交点通過地方 太陽時 LST（Local Sun Time）は日に日に遅くなる。 イオンエンジンを稼働する高度 $268 \mathrm{~km}$ 以下では電力 確保のため, 軌道面と太陽方向のなす $\beta$ 角 $<-60^{\circ}$ とし て日除時間を短くしており，LST 16時以降の観測に なる。

電力確保のため, 軌道遷移期間中は図 5 (左) の太 陽指向姿勢とし，高度保持期間中は図 5 (中)の $+\mathrm{Y}$ 軸 地球指向姿勢が基本となる。光学観測の際には図 5 (右) の $+Z$ 軸地球指向姿勢に変更する。

図 6 に示す小型高分解能光学センサSHIROP (Small and High Resolution Optical Sensor) はパン
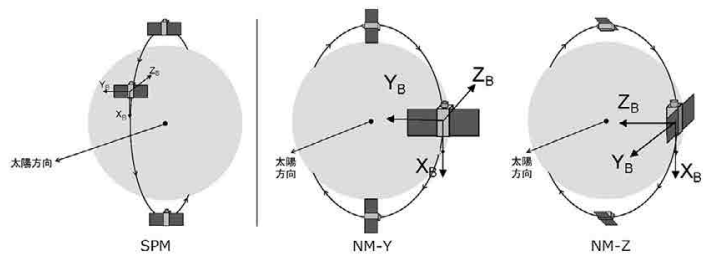

図 5 . SLATS 姿勢モード

(左：太陽指向, 中 : $+Y$ 軸地球指向, 右 $:+Z$ 軸地球指向)

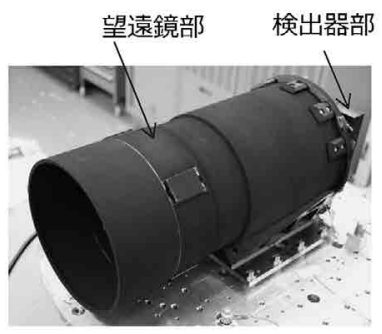

SHIROP光学部

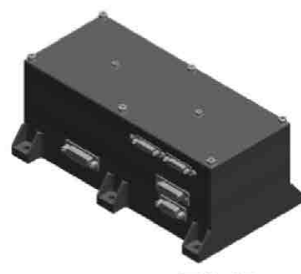

SHIROP電気部
図 6.SHIROP 外観図

表 3 . 光学センサ SHIROP 主要諸元

\begin{tabular}{|l|l|}
\hline \multicolumn{1}{|c|}{ 項目 } & \multicolumn{1}{c|}{ 諸元 } \\
\hline 望遠鏡方式 & カセグレン型 \\
\hline 有効開口径 & $20 \mathrm{~cm}$ \\
\hline 焦点距離 & $2 \mathrm{~m}$ \\
\hline 波長 & $0.48-0.7 \mu \mathrm{m}$ \\
\hline 検出器 & 2 次元 CCD \\
\hline 撮像方式 & 時間遅延積分 (最大 64 段, 可変) \\
\hline GSD & $1 \mathrm{~m}$ 以下 (高度 $268 \mathrm{~km})$ \\
\hline $\begin{array}{l}\text { 視野角 } \\
\text { FOV }\end{array}$ & $\begin{array}{l}0.5 \mathrm{deg} \text { 以上 } \\
\text { 高度 } 220 \mathrm{~km} \text { で観測幅 } 2 \mathrm{~km} \text { 相当) }\end{array}$ \\
\hline SNR & $\begin{array}{l}25 \text { 以上 (高度 } 268 \mathrm{~km}, \text { 北緯 } 35.7^{\circ} \\
\text { 春分・ LST } 16: 30, \text { 反射率 } 10 \%)\end{array}$ \\
\hline $\mathrm{MTF}$ & 0.08 以上 (高度 $268 \mathrm{~km})$ \\
\hline 質量 & $\begin{array}{l}19.8 \mathrm{~kg} \\
\text { 光学部 : } 16.9 \mathrm{~kg}, \text { 電気部 : } 1.9 \mathrm{~kg}\end{array}$ \\
\hline 電力 & $27.8 \mathrm{~W}$ \\
\hline
\end{tabular}

クロマチック観測を行う口径 $20 \mathrm{~cm}$ の望遠鏡であ り, +Z方向を指向し, スナップ撮像を行う。SHIROP 主要諸元を表 3 に示す。

軌道高度の低下に伴い, 観測幅や地上分解能 GSD (Ground Sampling Distance) が変化する。軌道高度 $400 \mathrm{~km}$ において GSD は $1.08 \mathrm{~m}$ の関係であり, 軌道高 度に応じて $7 \mathrm{~km} / \mathrm{s}$ 台の衛星の進行による直下の地表 移動距離が GSD と同じになる期間をコマンドにより $0.1 \mu \mathrm{s}$ 単位で設定可能である。

SHIROPはGPS 受信機を搭載しており, 撮像対象 の位置情報に対応して撮像時刻を自律的に決定する機 能を有する。

\section{4. 観測プロダクト}

SLATS は超低高度で地方時16時以降の観測となる ことから, CCD 出力信号を加算合成する時間遅延積分 TDI（Time Delay Integration）により S/N を向上さ 


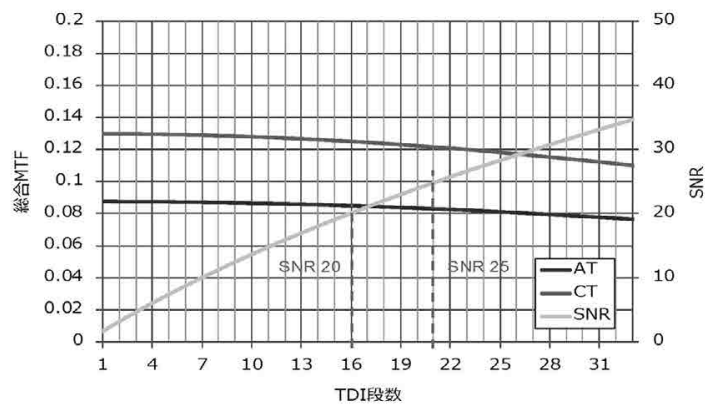

図 7. TDI 段数と $S / N$ 向上, MTF の関係

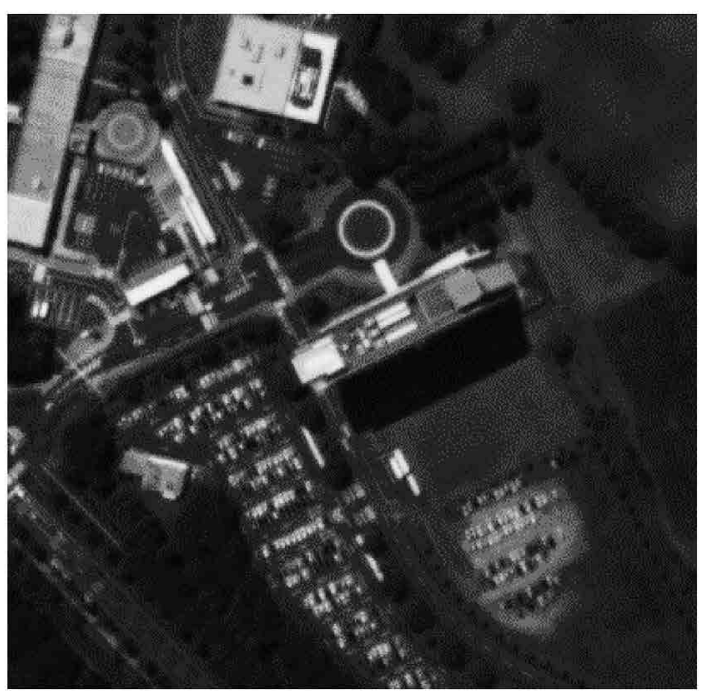

図 8.SHIROP シミュレーション画像 条件：高度 $268 \mathrm{~km}$, 北緯 $35.7^{\circ}$, 春分・LST $16: 30$

せる。TDI 段数と S/N 向上抒よびアロングトラック AT (衛星進行) 方向・クロストラック CT 方向の光学 伝達関数 MTF（Modulation Transfer Function）の 関係を図 7 に示す。また，高度 $268 \mathrm{~km} ，$ 北緯 $35.7^{\circ}$ ，春 分・LST 16：30の条件に打けるSHIROPによる撮像 シミュレーション画像を図 8 に示す。

超低高度では大気抵抗などにより軌道精度への影響 があり，撮像位置精度が低下寸る可能性がある。 SLATS では将来の地球観測に向け，技術的な観点で, 高度，LST，TDI 段数，イオンエンジン推力，大気抵 抗，ヨーステアリング（地球の自転による撮像対象の 動きに合わせた衛星姿勢の地心方向を軸とした補正で あり, 最大 64 段の TDIにより検出器上で 4 ピクセル程 度）が画像に及ぼす影響を評価する予定である。

SHIROP では 1 週間で40シーン程度を撮像する計 画である。基本的に直下を撮像し，必要に応じて X 軸

\begin{tabular}{|c|c|c|c|c|c|c|}
\hline 1日目 & 2日目 & 3日目 & 4日目 & 5日目 & 6日目 & 7日目 \\
\hline 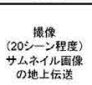 & 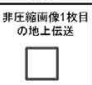 & 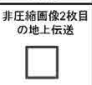 & 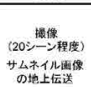 & 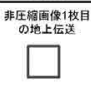 & 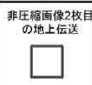 & \\
\hline 띠믐 & or & or & 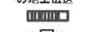 & or & or & 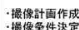 \\
\hline to & 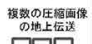 & 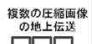 & ए & 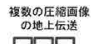 & 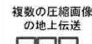 & 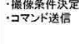 \\
\hline 地上詳伍 & $\square \square \square$ & $\square \square \square$ & 地上深的 & 口व口 & $\square \square \square$ & \\
\hline 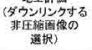 & b & W & 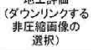 & 2 & ए & \\
\hline
\end{tabular}

図 9.SHIROP 運用プロファイル

回りに衛星姿勢を回転するロールポインティングを行

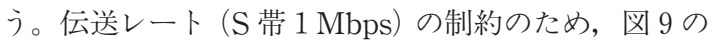
SHIROP 運用プロファイルに示すように, サムネイル を先に伝送し，地上に伝送する画像（1 週あたり非圧 縮 4 枚または圧縮12枚程度）を選択する。

\section{5 . 将来の実利用拡大への期待}

SLATS は将来の地球観測の実利用に向けた技術試 験機であり, 光学センサのほかレーダやレーザ光を用 いるライ夕゙など，観測地点との距離が近くなることで 利点が増す身近な観測プラットフォームとして利用が 拡大することが期待されている。SLATS での技術試 験結果を踏まえ，将来の地球観測構想に反映していく 計画である11。

図10に示す SLATS は，現在，システム PFT(プロ トフライト試験）を経て，開発を完了したところであ り，種子島での打上げに向けて作業を進めているとこ ろである。SLATSの今後の動向にご注目いただきた い。

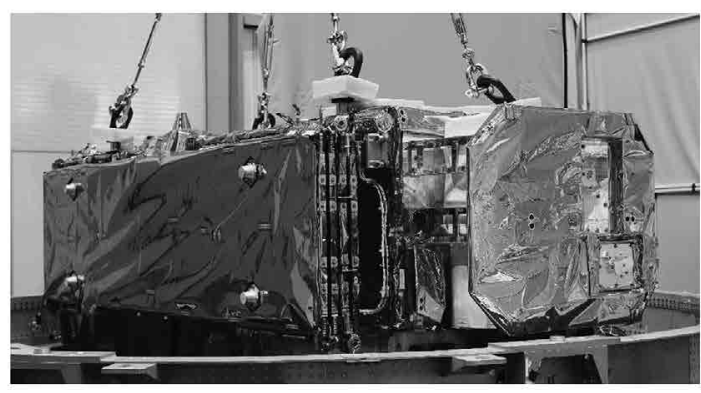

図10.システムPFT における SLATS

（受付日2017.9.5，受理日2017.10.13）

\section{参考文献}

1) Hoshino, H. et al., SLATS and Future Prospect -New viewpoints for Earth Observation-, 31st International Symposium on Space Technology and Science, 2017, 2017-n-09. 